\title{
Emotional Intelligence as Predictor of Compassion Fatigue among Mental Health Practitioners
}

\author{
Kabunga Amir ${ }^{1}$, Apio Betty², Anyolitho Maxson Kenneth ${ }^{2}$ \\ ${ }^{1}$ Department of Mental Health, Lira University, Lira, Uganda \\ ${ }^{2}$ Department of Public Health, Lira University, Lira, Uganda \\ Email: amirkabs2017@gmail.com
}

How to cite this paper: Amir, K., Betty, A. and Kenneth, A.M. (2019) Emotional Intelligence as Predictor of Compassion Fatigue among Mental Health Practitioners. Open Access Library Journal, 6: e5410. https://doi.org/10.4236/oalib.1105410

Received: April 18, 2019

Accepted: May 17, 2019

Published: May 20, 2019

Copyright () 2019 by author(s) and Open Access Library Inc.

This work is licensed under the Creative Commons Attribution International License (CC BY 4.0).

http://creativecommons.org/licenses/by/4.0/

\begin{abstract}
More than half of the professionals working with vulnerable population in high-income countries suffer from compassion fatigue, which has detrimental effects on mental health practitioners' wellbeing. This study was aimed at investigating the role of emotional intelligence in predicting compassion fatigue among mental health practitioners. Data collection was undertaken using surveys incorporating the Professional Quality of Life-5 and the Emotional Competency Inventory 2.0. Mental health practitioners from Northern Uganda participated with 207 respondents returning completed surveys. Data analysis procedures were undertaken using Fisher's exact test and logistical regression. The statistical hypotheses were tested at a significance level of $\mathrm{p} \leq 0.05$. The results revealed that self-management $(p=0.003)$ and social awareness $(p=$ 0.039 ) had a statistically significant effect on the prediction of compassion fatigue in mental health practitioners. The results equally indicated that respondents who recorded low levels of self-management were 4 times more likely to report compassion fatigue than those who had registered high levels of self-management. It was also found that a relative increase in social awareness was associated with a lower rating of compassion fatigue $(\mathrm{OR}=1.24)$. Based on these findings, recommendations were made to include emotional intelligence as an integral component of training and incorporate emotional intelligence intervention techniques to benefit mental health practitioners in managing compassion fatigue.
\end{abstract}

\section{Subject Areas}

Psychology

\section{Keywords}

Compassion Fatigue, Emotional Intelligence, Mental Health Practitioners, 
Uganda

\section{Introduction}

Compassion fatigue is one of the biggest health problems facing mental health practitioners with close to $50 \%$ being at risk of this phenomenon [1]. In America, a study by Borntrager et al. revealed that about $75 \%$ mental health practitioners had a significant level of compassion fatigue [2]. Studies have found that almost $6 \%$ of mental health practitioners had used drug and alcohol before meeting clients [3], while $80 \%$ of the sample reported having gone to work with a hangover [4]. The core effect of unaddressed compassion fatigue is suicide. Pope and Tabachnick [5] discovered that $29 \%$ of their sample of 800 mental health practitioners reported suicidal ideation at some point during their career and in fact $4 \%$ of professionals had attempted suicide. It is on this account that Johne [6] depicts the phenomenon of compassion fatigue as death by a thousand cuts. Such psychological issues among mental health practitioners are attributed to unaddressed compassion fatigue.

The prevalence of compassion fatigue among mental health practitioners in Africa is similar to that seen in other continents. Wilson's [7] study targeting the existence of compassion fatigue among trauma counsellors in South Africa. In Kenya, a study conducted by Nyagaya, Chepchieng, Njonge and Ombura [8] reported prevalence levels of $48.2 \%$ for high to severe compassion fatigue. In Uganda, most studies have concentrated on primary victims of war [9] while little attention has been directed to the caregivers. However, studies have revealed that symptoms of compassion fatigue are prevalent among the mental health practitioners working in northern Uganda [10] [11]. Such psychological challenges in the region are more prominent due to the effects of the protracted Lord's Resistance Army conflict that lasted 20 years. Mass rape, torture, brutal killings, forced marriages, mutilations, abductions of children, men and women were used systematically as war tactics [12]. The region needed more psychotherapy interventions for total healing from the horrors of the war. Psychotherapy has been recognized as a demanding profession, even in the finest circumstances. But operating in the volatile and highly charged circumstances like northern Uganda may be a more emotionally draining and physically exhausting experience for even the most competent and experienced mental health practitioners.

Most mental health practitioners enter the field with the intent to provide compassionate care for clients experiencing mental, emotional and physical pain. However, literature on the health of mental health practitioners leaves little doubt that their work takes a toll on their psychological and emotional wellbeing [13] [14]. They observe the trauma and emotions registered by survivors almost daily. The constant exposure to clients' distress may become emotionally strenuous on mental health practitioners who may suffer from compassion fatigue 
[13] [14]. Individuals differ in relation to their ability to practice effective control over their emotions. Such individual differences are attributed to differences in emotional intelligence [15]. On the basis of a theoretical framework proposed by Salovey and Mayer [15], it can be assumed that higher levels of emotional intelligence can improve psychological wellbeing and thus reduce compassion fatigue.

There are numerous studies that have considered factors that predict compassion fatigue within mental health professionals although few studies have considered specifically role of emotional intelligence as a predictor. Additionally, most of these are based in western countries. These studies have shown variables like age gender; supervision, levels of exposure to traumatic materials, levels of social network and levels of empathy [16]. Emotional intelligence has been targeted as a popular area of study by researchers in several fields. Goleman [17], postulated that emotional intelligence has four fundamentals which include; self-awareness, self-management, social awareness and social skills. Mayer, Salovey and Caruso [18] noted that emotional intelligence is one of the best predictors of psychological wellbeing. Past studies have only reported significant correlations between emotional intelligence and compassion fatigue [19]. But the recognition of emotional intelligence by mental health practitioners may be the edge necessary not only to make effective and relevant connections with clients but also effectively deal with work-related stress. An understanding of the application of emotional intelligence to psychotherapy cannot be underrated given the fact that it enhances personal effectiveness and improves outcomes.

Studies show that higher levels of emotional intelligence are positively related to assertiveness, willingness to use social support networks, better problem-solving skills, adaptation and a lower level of anxiety [20]. Individuals with high emotional intelligence are less prone to work-related problems. Conversely, individuals low on emotional intelligence tend to have higher levels of work-related stress, engage in self-destructive behaviours including; drinking alcohol, smoking and blame colleagues for their mistakes [20] [21]. A report exploring child protection in England found that there was a need for mental health practitioners to develop emotional intelligence to manage the work related challenges [22]. However, researchers acknowledge the inadequate attention mental health practitioners have received in literature. Figley [23] indicated that mental health practitioners are vulnerable to compassion fatigue as a result of their jobs, yet limited studies can identify the elements that are associated with this job-related problem. Austin, Goble, Leier and Byrne [24] stress that existing research fails to fully explain the personal and professional factors that influence the development of compassion fatigue. Robinson-Keilig [25] stressed the need to understand the phenomenon of compassion fatigue among mental health practitioners. Indeed, without understanding this phenomenon, the profession may end up being devoid of competent and experienced mental health practitioners.

While the prevalence levels of compassion fatigue among mental health practitioners seem to be high disastrous effects, many mental health practitioners 
have limited knowledge concerning the identification of the symptoms of this problem. Given the significant research indicating that mental health practitioners providing services to vulnerable populations are likely to develop compassion fatigue, it is critically important that organizations and individuals devote greater attention to create greater awareness of risk factors and symptoms associated it. Sadly, most of the studies on compassion fatigue have focused on the western geographical setting and minimal research has been conducted in the developing world. In addition, there exists limited research on how emotional intelligence is related to compassion fatigue among mental health practitioners yet emotional intelligence is a personal attribute or resource that may predict compassion fatigue among mental health practitioners. To establish this, a hypothesis was advanced: a linear relationship exists between the predictor variables and the development of compassion fatigue among mental health practitioners.

\section{Methods}

A correlational predictive research design was used in this study. The researchers were interested in identifying predictive relationship between emotional intelligence and compassion fatigue among mental health practitioners.

\subsection{Participants}

The present study investigated mental health practitioners working in northern Uganda. A total of 220 respondents completed the survey. Among the 220 participants, 13 did not complete the questionnaires and these cases were excluded from data analysis. Thus, the sample consisted of 207 mental health practitioners employed in northern Uganda. The majority of the respondents, that is $41.5 \%$ (n $=86$ ) are in the age group $25-34$ years. The majority of the respondents were male, constituting $56 \%$ of the sample $(n=116)($ Table 1$)$.

\subsection{Measures}

To measure emotional intelligence and compassion fatigue, Emotional Competency Inventory 2.0 and the Professional Quality of Life-5 were respectively used.

Table 1. Demographic information of respondents.

\begin{tabular}{ccc}
\hline Category & N & Percentage \\
\hline Age & 86 & \\
$25-34$ & 75 & 41.5 \\
$34-44$ & 40 & 36.2 \\
$45-54$ & 6 & 19.3 \\
55 and Above & & 2.9 \\
Gender & 116 & 56 \\
Male & 91 & 44 \\
Female &
\end{tabular}


ECI 2.0 is a 360-degree tool standardized by the Hay Group in 2002. The ProQOL5 scale developed by Stamm [26] has thirty items measuring compassion satisfaction, compassion fatigue and burnout but only ten items that measure compassion fatigue were completed by the respondents. The levels of compassion fatigue were computed as a sum of all the scores. Both tools were found to be valid and reliable [26] [27].

\subsection{Procedure}

Eight meetings, four per district, were organised with the mental health practitioners through the Directors of the psychotherapy centres. The purpose of the study, the methods of data collection and time frame for the study were explained to the mental health practitioners at the meetings. The questionnaires were hand-delivered by the researchers to the prospective respondents. The respondents were then invited to participate in the study. The completed instruments were collected on the same day.

\subsection{Ethical Consideration}

The study was reviewed and cleared by the Research and Ethics Committee from the National HIV/AIDS Research Committee of Makerere University. Permission to conduct the study was also sought from the Uganda National Council for Science and Technology. The questionnaires were distributed to those who volunteered to participate. All respondents were assured that their participation was anonymous, confidential and voluntary. In order to observe confidentiality, the mental health practitioners were not required to sign a consent form.

\subsection{Data Analyses}

The data was coded and entered into the computer. Data analysis was undertaken using Statistical Package for the Social Sciences. A Logistic regression model was constructed to discover whether the elements of emotional intelligence (social awareness, self-awareness, self-management and social skills) are predictive of compassion fatigue. The dependent variable (emotional intelligence) in this study was transformed into dichotomous with individuals who had compassion fatigue being coded as 1 and those that did not have compassion fatigue being coded as 0 .

\section{Results}

Logistic regression analysis was conducted to examine the extent to which self-awareness, social awareness, self-management and social skills could predict the likelihood of mental health practitioners developing compassion fatigue. The full model containing all predictors was statistically significant, $\chi^{2}(4, \mathrm{~N}=207)=$ $72.25, \mathrm{p}<0.001$, indicating that the model was able to distinguish between respondents who reported and those that did not report compassion fatigue. The model as a whole explained between 29.9\% (Cox and Snell R square) and 50.1\% 
(Nagelkerke R squared) of the variance in compassion fatigue status. Execution of an $X^{2}$ Test of Goodness of Fit, the Hosmer and Lemes how Test, indicated a $X^{2}$ $=7.404, \mathrm{df}=8$, and $\mathrm{p}=0.404$ supporting the model as having good predictive capacity and rejection of the null hypothesis. This information is summarized in Table 2.

Further, logistic regression analysis was conducted to examine the extent to which self-awareness, social awareness, self-management and social skills could predict the likelihood of mental health practitioners developing compassion fatigue. The dependent variable in this study was transformed into dichotomous with individuals who had compassion fatigue being coded as 1 and those that did not have compassion fatigue being coded as 0 . This satisfies the first assumption of logistic regression analysis. Furthermore, the independent variables (self-awareness, social awareness, self-management and social skills) in this study are all continuous, meeting the second assumption. Simultaneous entry of the independent variables as predictors into a logistic regression model addressed the development of high-risk levels for compassion fatigue in mental health practitioners. The results are summarized in Table 3.

Table 3 shows that the model contained four independent variables (selfawareness, social awareness, self-management, social skills). As shown in Table 3, it

Table 2. Omnibus tests of model coefficients, model summary, Hosmer and Lemeshow test.

\begin{tabular}{ccccc}
\hline \multicolumn{5}{c}{ Omnibus Tests of Model Coefficients } \\
& Chi-square & Df & \\
\multirow{2}{*}{ Step 1 } & Step & 72.245 & 4 & p-value \\
& Block & 72.245 & 4 & 0.000 \\
& Model & 72.245 & 4 & 0.000 \\
& & Model Summary & & 0.000 \\
\hline \multirow{2}{*}{ Step } & -2 Log likelihood & Cox \& Snell R Square & Nagelkerke R Square \\
1 & 107.975 & 0.299 & 0.509 \\
\hline \multirow{2}{*}{ Step } & Hosmer and Lemeshow Test & & \\
1 & Chi-square & Df & p-value \\
\hline
\end{tabular}

Table 3. Logistic regression: predicting compassion fatigue.

\begin{tabular}{cccccc}
\hline Variables & $\beta^{b}$ & SE & Wald test & p-Value & OR $^{c}(95 \%$ CI $)$ \\
\hline Self-Awareness & -0.171 & 0.103 & 2.734 & 0.098 & 0.84 (95\% CI: $0.69-1.03)$ \\
Social Awareness & 0.217 & 0.105 & 4.264 & 0.039 & 1.24 (95\% CI: $1.01-1.53)$ \\
Self-Management & -0.153 & 0.052 & 8.574 & 0.003 & 3.7 (95\% CI: $1.30-11.01)$ \\
Social Skills & -0.060 & 0.054 & 1.210 & 0.271 & 0.94 (95\% CI: $0.84-104)$ \\
\hline
\end{tabular}

Variable(s) entered: Self-Awareness; Social Awareness; Self-Management; Social Skills. 
was found that the levels of self-management $(\mathrm{p}=0.003)$ and social awareness ( $\mathrm{p}$ $=0.039)$ had a statistically significant effect on the prediction of compassion fatigue incidence in mental health practitioners. The strongest predictor of reporting compassion fatigue was self-management recording an odds ratio of 3.7. This indicated that respondents who had low levels of self-management were almost 4 times more likely to report compassion fatigue than those who had high levels of self-management, controlling for all other factors in the model. It was also found that a relative increase in social awareness was associated with a lower rating of compassion fatigue $(\mathrm{OR}=1.24)$. This can be interpreted that with an increase in social awareness, the participant is at least more than one time more likely to register a lower level of compassion fatigue. The results suggest that the inability to manage strong negative emotions and failure to understand the emotions of others is sufficient to exacerbate the negative impact of compassion fatigue.

\section{Discussion}

Compassion is the core value of care giving that provides mental health practitioners with passion and hopefulness in the face of hopelessness [28]. However, constantly dealing with the psychological and emotional needs of clients is demanding and sometimes mental health practitioners end up ignoring their own emotional and psychological needs leading to compassion fatigue. Given the personal consequences of compassion fatigue, it is important that mental health practitioners are empowered to be able to predict it. Therefore, the main purpose of the study was to examine the role of emotional intelligence in predicting compassion fatigue among mental health practitioners. Ruiz-Aranda, Extremera, and Pineda-Galán [29] suggest that there is a relationship between emotional intelligence, psychological and emotional wellbeing in professionals. However, there is limited research targeting the role of emotional intelligence in predicting compassion fatigue among mental health practitioners. When the relationship between the sub-dimensions of emotional intelligence and compassion fatigue was examined, it was noted that both self-management and social awareness make a positive contribution in predicting the development of compassion fatigue. This implies that when mental health practitioners manage their own emotions and understand the emotions of others, the possibility of experiencing compassion fatigue decreases. Managing emotions is particularly important in contributing to a decrease in compassion fatigue. This view is supported by Keefer et al., [30] who argued that the inability to regulate strong negative emotions exacerbates the negative impact of stress on health through potentially harmful coping behaviours such as; smoking, drinking and eating fatty foods.

The results of this study confirm previous studies [31] [32] [33] [34]. These studies found out that among the components of emotional intelligence components, self-management and social awareness could significantly predict work related stress. The findings also support the results of Jennings and Greenberg 
[35] studies which indicated that social awareness leads individuals to preserve healthier relationships and they find it easier to deal with everyday problems and manage anxiety. Bar-On [36] reported that the abilities of understanding one's own emotions, setting goals in order to develop one's own potentials, and seeing events in the right perspective are the most important factors of subjective well-being.

\section{Conclusion}

The present study attempted to provide an enhanced conceptualisation of the influence of emotional intelligence on compassion fatigue among mental health practitioners. Results show that the levels of self-management and social awareness had a statistically significant effect on the prediction of compassion fatigue incidence among mental health practitioners. Hence, the strongest predictor of compassion fatigue was self-management. Therefore, controlling compassion fatigue requires an underlying ability in emotional intelligence fundamentals, specifically social awareness and self-management. Mental health practitioners should therefore guard against generally provoking anger, resentment or confusion by strongly displaying emotions, but rather deal constructively with, work-related stress and conflict to facilitate the accomplishment of tasks at hand.

\section{Conflicts of Interest}

The authors declare no conflicts of interest regarding the publication of this paper.

\section{References}

[1] Injeyan, M.C., Shuman, C., Shugar, A., Chitayat, D., Atenafu, E.G. and Kaiser, A. (2011) Personality Traits Associated with Genetic Counsellor Compassion Fatigue: The Roles of Dispositional Optimism and Locus of Control. Journal of Genetic Counselling, 20, 526-540. https://doi.org/10.1007/s10897-011-9379-4

[2] Borntrager, C., Caringi, J.C., van den Pol, R., Crosby, L., O’Connell, K., Trautman, A. and McDonald, M. (2012) Secondary Traumatic Stress in School Personnel. Advances in School Mental Health Promotion, 5, 38-50. https://doi.org/10.1080/1754730X.2012.664862

[3] Pope, K.S., Tabachnick, B.G. and Keith-Spiegel, P. (1987) Ethics of Practice: The Beliefs and Behaviors of Psychologists as Therapists. American Psychologist, 42, 993-1006. https://doi.org/10.1037/0003-066X.42.11.993

[4] Thoreson, R., Miller, M. and Krauskopf, C.J. (1989) The Distressed Psychologist: Prevalence and Treatment Considerations. Professional Psychology. Research and Practice, 20, 153-158. https://doi.org/10.1037/0735-7028.20.3.153

[5] Pope, K.S. and Tabachnick, B.G. (1994) Therapists as Patients: A National Survey of Psychologists' Experiences, Problems, and Beliefs. Professional Psychology. Research \& Practice, 25, 247-258. https://doi.org/10.1037/0735-7028.25.3.247

[6] Johne, M. (2006) Compassion Fatigue: A Hazard of Caring Too Much. Medical Post, 42, 3, 1-4.

[7] Wilson, K.L. (1998) An Exploratory Study into Secondary Traumatic Stress in 
Trauma/Crisis Counsellors and the Perceived Effectiveness of Supervision as a Debriefing Process and Coping Mechanism. Unpublished Masters Dissertation, University of Witwatersrand, Johannesburg.

[8] Nyagaya, L., Chepchieng, M., Njonge, T. and Ombura, J. (2014) Secondary Traumatic Stress among Psychotherapists: An Empirical Comparative Analysis of Prevalence Rates and Management in Nakuru and Nairobi Counties of Kenya. Kenya Journal of Educational Planning, Economics \& Management, 8, 1-15.

[9] Akello, G., Reis, R. and Richters, A. (2010) Silencing Distressed Children in the Context of War in Gulu and Amuru in Uganda: An Analysis of Its Dynamics and Its Health Consequences. Social Science \& Medicine, 71, 213-220. https://doi.org/10.1016/j.socscimed.2010.03.030

[10] Ager, A., Pasha, E., Yu, G., Duke, T., Eriksson, C. and Cardozo, B.L. (2012) Stress, Mental Health, and Burnout in National Humanitarian Aid Workers in Gulu and Amuru in Uganda. Journal of Traumatic Stress, 25, 713-720. https://doi.org/10.1002/jts.21764

[11] Kabunga, A. and Muya, F.K. (2014) Work Stress and Coping Strategies among Social Workers: A Case of Northern Uganda. International Journal of Liberal Arts and Social Science, 2, 33-38.

[12] Annan, J., Blattman, C., Carlson, K. and Mazurana, D. (2008) The State of Female Youth in Gulu and Amuru in Uganda: Findings from the Survey of War-Affected Youth. Phase II. Survey of War-Affected Youth.

[13] Hildebrandt, L. (2012) Providing Grief Resolution as an Oncology Nurse Retention Strategy: A Literature Review. Clinical Journal of Oncology Nursing, 16, 601-606. https://doi.org/10.1188/12.CJON.601-606

[14] Lindberg, D. (2012) When Your Patients Die: Living with Cumulative Grief. ONS Connect, 10, 10-14.

https://www.Ons.Org/Search?Search_Api_Views_Fulltext=Publications\%20journals $\% 20$ connect

[15] Salovey, P. and Mayer, J.D. (1990) Emotional Intelligence. Imagination, Cognition and Personality, 9, 185-211. https://doi.org/10.2190/DUGG-P24E-52WK-6CDG

[16] Craig, C.D. and Sprang, G. (2010) Compassion Satisfaction, Compassion Fatigue, and Burnout in a National Sample of Trauma Treatment Therapists. Anxiety, Stress and Coping, 23, 319-339. https://doi.org/10.1080/10615800903085818

[17] Goleman, D. (2004) Judgments of Stress, Hazard, Risk and Danger. Human Factors and Ergonomics Society Annual Meeting Proceedings, Consumer Products, 503-507.

[18] Mayer, J.D., Salovey, P. and Caruso, D.R. (2004) Emotional Intelligence: Theory, Findings and Implications. Psychological Inquiry, 60, 197-215.

https://doi.org/10.1207/s15327965pli1503_02

[19] Lin, D.T., Liebert, C.A., Tran, J., Lau, J.N. and Salles, A. (2016) Emotional Intelligence as a Predictor of Resident Well-Being. Journal of American College of Surgeons, 223, 352-358. https://doi.org/10.1016/j.jamcollsurg.2016.04.044

[20] Poret, J., Barriball, L., Fitzpatrick, J. and Roberts, J. (2010) Emotional Intelligence: Its Relationship to Stress, Coping, Wellbeing and Professional Performance in Nursing Students. Nurse Education Today, 31, 855-860. https://doi.org/10.1016/j.nedt.2010.12.023

[21] Kun, B. and Demetrovics, Z. (2010) Emotional Intelligence and Addictions: A Systematic Review. Substance Use \& Misuse, 45, 1131-1160. 
https://doi.org/10.3109/10826080903567855

[22] Kinman, G. and Grant, L. (2011) Exploring Stress Resilience in Trainee Social Workers: The Role of Emotional and Social Competencies. British Journal of Social Work, 41, 261-275. https://doi.org/10.1093/bjsw/bcq088

[23] Figley, C.R. (2003) Fishing Lessons for Treating the Traumatized: History of the Traumatology Certification Program. Traumatology, 9, 187-192. https://doi.org/10.1177/153476560300900402

[24] Austin, W., Goble, E., Leier, B. and Byrne, P. (2009) Compassion Fatigue: The Experience of Nurses. Ethics and Social Welfare, 3, 195-214. https://doi.org/10.1080/17496530902951988

[25] Robinson-Keilig, R.A. (2010) An Investigation of Interpersonal Disruptions and Secondary Traumatic Stress among Mental Health Therapists. Open Access Theses and Dissertations from the College of Education and Human Sciences, 85. http://digitalcommons.unl.edu/cehsdiss/85

[26] Stamm, B.H. (2010) The Concise ProQOL Manual. 2nd Edition, ProQOL.org, Pocatello.

[27] Hay Group (2005) Emotional Competence Inventory (ECI) Technical Manual. Steven B. Wolff, Boston.

[28] Bush, N.J. (2009) Compassion Fatigue: Are You at Risk? Oncology Nursing Forum, 36, 24-28. https://doi.org/10.1188/09.ONF.24-28

[29] Ruiz-Aranda, D., Extremera, N. and Pineda-Galán, C. (2014) Emotional Intelligence, Life Satisfaction and Subjective Happiness in Female Student Health Professionals: The Mediating Effect of Perceived Stress. Journal of Psychiatric and Mental Health Nursing, 21, 106-113. https://doi.org/10.1111/jpm.12052

[30] Keefer, K.V., Parker, J.D.A. and Saklofske, D.H. (2009) Emotional Intelligence and Physical Health. In: Stough, C., Saklofske, D.H. and Parker, J.D.A., Eds., The Springer Series on Human Exceptionality. Assessing Emotional Intelligence: Theory, Research, and Applications, Springer, Berlin, 191-218.

https://doi.org/10.1007/978-0-387-88370-0_11

[31] Montes-Berges, B. and Augusto, J.M. (2007) Exploring the Relationship between Perceived Emotional Intelligence, Coping, Social Support and Mental Health in Nursing Students. Journal of Psychiatric Mantel Health Nursing, 14, 163-171. https://doi.org/10.1111/j.1365-2850.2007.01059.x

[32] Naidoo, S. and Pau, A. (2008) Emotional Intelligence and Perceived Stress. SADJ: Journal of the South African Dental Association, 63, 148-151.

[33] Bokharaeian, E., SetareSobh, S., Rahimi, M. and Zare, M. (2014) The Relationships between Emotional Intelligence, Time Management, and Job Stress among Employees in Shahr Bank. Applied Mathematics in Engineering, Management and Technology, 856-861.

[34] Killian, K.D. (2008) Helping Till It Hurts? A Multi-Method Study of Compassion Fatigue, Burnout, and Self-Care in Clinicians Working with Trauma Survivors. Traumatology, 14, 32-44. https://doi.org/10.1177/1534765608319083

[35] Jennings, P.A. (2011) Promoting Teachers' Social and Emotional Competencies to Support Performance and Reduce Burnout. In: Cohan, A. and Honigsfeld, A., Eds., Breaking the Mold of Preservice and Inservice Teacher Education: Innovative and successful Practices for the Twenty-First Century, Rowman \& Littlefield; New York, 133-143.

[36] Bar-On, R. (2005) The Impact of emotional Intelligence on Subjective Well-Being. Perspectives in Education, 23, 41-62. 